\title{
Determining Functional Vitamin B12 Deficiency in the Elderly
}

\author{
Niloofar Khodabandehloo ${ }^{1}$; Masoud Vakili ${ }^{2}$; Zahra Hashemian ${ }^{3,{ }^{*}}$; Hadi Zare Zardini ${ }^{3,4}$ \\ ${ }^{1}$ Department of Internal Medicine, Tehran University of Medical Sciences, Tehran, IR Iran \\ 2 Department of Hematology and Oncology, Tehran University of Medical Sciences, Tehran, IR Iran \\ ${ }^{3}$ Department of Pediatrics, Hematology, Oncology and Genetics Research Center, Shahid Sadoughi University of Medical Sciences, Yazd, IR Iran \\ 4 Young Researchers and Elite Club, Yazd Branch, Islamic Azad University, Yazd, IR Iran \\ ${ }^{*}$ Corresponding Author:Zahra Hashemian, Department of Pediatrics, Hematology, Oncology and Genetics Research Center, Shahid Sadoughi University of Medical Sciences, Yazd, IR \\ Iran, Tel: +98-3518224000, Fax: +98-3518224100, E-mail: zhashemian@yahoo.com \\ Received: June 23, 2013; Revised: January 29, 2014; Accepted: December 14, 2014
}

\begin{abstract}
Background: Elevated concentration of serum total homocysteine usually occurs in vitamin B-12 deficiency. This metabolite can be measured and used for screening functional vitamin B-12 deficiency.

Objectives: We assessed functional vitamin B12 deficiency in Tehranian elderly admitted to elderly research center, University of Social Welfare and Rehabilitation Sciences.

Patients and Materials: A cross-sectional study was performed on 232 elderly admitted to elderly research center in Tehran, Iran in 2012. According to other studies, individuals were classified into two groups: high risk of vitamin B-12 deficiency $(<220$ pmol/L) and borderline vitamin B-12 (220-258 pmol/L) accompanied by elevated homocysteine (>15 micmol/L).

Results: Cut-off of $15.0 \mathrm{pmol} / \mathrm{L}$ for homocysteine was identified for persons with normal or elevated concentrations. Among persons aged $65-74$ and $\geq 75$ years, respectively, $56 \%$ and $93 \%$ were at high risk of vitamin B-12 deficiency.

Conclusions: The prevalence of B12 deficiency was higher in this study compared to other studies, so more attention and massive efficacious policy should be designed to reduce the deficiency of this vitamin.
\end{abstract}

Keywords: Vitamin B12 Deficiency; Homocysteine; Elderly; Concentration

\section{Background}

According to the findings of previous studies, malnutrition is the most common cause of vitamin B12 deficiency, but the metabolism of this vitamin may be affected by other factors such as smoking and alcohol consumption, diseases, drugs and enzyme defects etc. (1). Although, this deficiency may be developed in persons with low body storage of vitamin B12 As well as people who have malabsorption or defected metabolism of vitamin B12 and those with physiological conditions with increased demands such as pregnancy and breastfeeding. Longterm deficiency of this vitamin causes different diseases such as neurological and gastrointestinal disorders and anemia $(2,3)$. Moreover, absorption and reabsorption of vitamin B12 is decreased because of ageing of intestinal mucosa $(4,5)$. The frequency of high total serum homocysteine is related to age and hyperhomocysteinemia is common in old people and negatively correlated with cognitive status. It may be that deficiency of folate, vitamin B6 and vitamin B12 have an important role in cognitive impairment in the elderly through hyperhomocysteinemia (6). On the other hand, elevated plasma homocysteine concentration is a sensitive marker to evaluate vitamin B12 and folate deficiency. Elevated circu- lating total homocysteine (tHcy) concentration is a risk factor for cardiovascular disease. In addition, HHcy in the elderly is strongly associated with depression, impaired cognitive function and dementia (7-10). Few studies demonstrated that slight cognitive impairment might be an early symptom. However, few studies were published on other possible early signs and symptoms. In clinical practice, vitamin B12 deficiency is often suspected in elderly patients reporting vague symptoms (1).

\section{Objectives}

The aim of this study was to determine the frequency of vitamin B12 deficiency in the elderly population of Tehran, using serum total homocysteine as the indicator of tissue vitamin deficiency.

\section{Patients and Materials}

The study population comprised a random sample of 232 elderly inhabitants of Tehran aged $\geq 65$ years who admitted to the elderly research center, University of Social Welfare and Rehabilitation Sciences. This study was performed in Tehran, Iran in 2012. The samples were

Copyright (C) 2015, Iranian Red Crescent Medical Journal. This is an open-access article distributed under the terms of the Creative Commons Attribution-NonCommercial 4.0 International License (http://creativecommons.org/licenses/by-nc/4.0/) which permits copy and redistribute the material just in noncommercial usages, provided the original work is properly cited. 
collected from two centers by considering $\mathrm{a}=0.05$ and $\mathrm{d}=0.06$ in the elderly with about $15 \%$ of folic acid and vitamin B12 deficiency, and the factor/coefficient of two was considered for the design effect of sample size formula. This ratio was calculated for about 300 people. However, due to financial limitations because of tariff increases, 232 elderly people were enrolled in the study. Medical history (including pernicious anemia), smoking, consumption of multivitamin supplements and other aspects of health and lifestyle of participants were collected. Venous blood was obtained from all participants into evacuated serum tubes to analyze vitamin and metabolites status and in another evacuated test tube containing EDTA for a full blood count. An insulated box was used to transfer blood samples to the laboratory where the samples were stored at $-20^{\circ} \mathrm{C}$ for $0.5-2$ hours before centrifugation. Whole blood samples were centrifuged immediately (3000 grams, 10 minutes, $24^{\circ} \mathrm{C}$ ) after arrival and serum samples were stored at $-80^{\circ} \mathrm{C}$. An informed written consent was obtained from all participants before entering the study. Serum homocysteine concentrations were measured using a fluorescence polarization immunoassay and an autoanalyzer. Repeated homocysteine measurements were performed in 100 individuals by gas chromatography-mass spectrometry (GCMS) at another laboratory and the correlation coefficient between the GCMS and FPIA homocysteine assays was 0.99. MMA assays were not performed because of technical problems. Vitamin B-12 determination was made by a competitive protein binding assay with an automated chemiluminescence detection system with an analytic imprecision of $<10 \%$. Individuals were classified as high-risk for vitamin B-12 deficiency if they had very low levels of vitamin B-12 ( $<150 \mathrm{pmol} / \mathrm{L})$. According to another classification, high-risk was defined as low (< 220 pmol/L) or borderline vitamin B-12 (200-220 pmol/L) concentrations accompanied by elevated homocysteine (>15 mol/L) concentrations (11).

\subsection{Statistical Analysis}

Continuous variables were presented as means and SDs. Differences in the mean values of biochemical indexes were compared by analysis of covariance or tests for linear trend across groups. Variables without a normal distribution were transformed to the logarithmic form. Associations of homocysteine with age, gender, vitamin B-12 and creatinine were assessed by spearman correlation. All analyses were performed with SPSS version 15 (IBM,USA).

\section{Results}

Totally, 232 patients who the inclusion criteria entered the study. Of them, $102(44 \%)$ were male. The mean age of participants was $73.8 \pm 5$ years $[<75$ years: $n=146(62.9 \%)$, $>75$ years: $n=86(37.1 \%)]$. Table 1 shows the characteristics of the study population and Table 2 presents the charac- teristics by age and gender. The mean serum concentration of homocysteine was higher in the older age group than the younger age group, while the mean B12 concentration was higher in the younger age group $(\mathrm{P}<0.001)$. Mean homocysteine and hemoglobin concentrations were higher in men than women $(\mathrm{P}<0.001)$. The correlation between metabolite and age in all participants is shown in Table 3. As this table shows, there was a significant negative correlation between age and hemoglobin and B12, and between B12 and homocysteine; besides, there was a statistically significant positive correlation between age and MCV, and between creatinine and homocysteine $(\mathrm{P}=0.001)$. The frequency $(\%)$ of vitamin $\mathrm{B} 12$ deficiency in all patients regarding B12 $<150 \mathrm{pmol} / \mathrm{L}$ and $<220 \mathrm{pmol} / \mathrm{L}$ was 50 (21.6\%), 93 (41.1\%), respectively. The prevalence (\%) of patients with borderline deficiency and homocysteine $\geq 15 \mathrm{micmol} / \mathrm{L}$ was $18(7.8 \%)$. Therefore, total prevalence of B12 deficiency, considering this borderline group with an elevated homocysteine level ( $\geq 15 \mathrm{micmol} / \mathrm{L}$ ) and those with $\mathrm{B} 12<220 \mathrm{pmol} / \mathrm{L}$, was 111 (47.9\%), known as high-risk subjects. The frequency (\%) of vitamin B-12 concentrations for each age and genderspecific category is separately shown in Table 4. In men, the prevalence of normal ( $\geq 258 \mathrm{pmol} / \mathrm{L}$ ), borderline (220-258 pmol/L), low ( $<220 \mathrm{pmol} / \mathrm{L})$ and very low $(<150$ $\mathrm{pmol} / \mathrm{L}$ ) vitamin B-12 concentrations were $49 \%, 12.7 \%, 38.2 \%$ and $20.6 \%$, respectively. The prevalence of normal to very low concentrations of vitamin B were $30.2 \%, 15.1 \%, 54.7 \%$ and $31.4 \%$ in older ( $\geq 75$ ) and $60.3 \%, 8.2 \%, 31.5 \%$ and $15.8 \%$ in younger patients $(<75)$, respectively. There was a downward shift to lower B12 concentrations in older patients. Thus, $56 \%$ of patients aged $65-74$ years and $93 \%$ of those aged $\geq 75$ years were at high-risk of vitamin B-12 deficiency. As mentioned earlier, there was a negative correlation between homocysteine and concentrations of vitamin B-12 $(r=-0.396)$. As shown in Table 5, the prevalence of very low $(<150 \mathrm{pmol} / \mathrm{L})$, low $(<220 \mathrm{pmol} / \mathrm{L})$ and borderline $(220-258 \mathrm{pmol} / \mathrm{L})$ B12 levels were 10, 5 and 3 times higher in the category with elevated homocysteine ( $\geq 15$ micmol/L), respectively.

Table 1. Characteristics of the Study Population ${ }^{\mathrm{a}}$

\section{Variables}

\begin{tabular}{lc}
\hline Age, $y$ & $73.7 \pm 5.2$ \\
\hline B12, pmol/L & $295 \pm 170$ \\
\hline Homocysteine, micmol/L & $19 \pm 7$ \\
\hline Hemoglobin, g/dL & $14 \pm 1.7$ \\
\hline MCV, FL & $92 \pm 7.2$ \\
\hline Creatinine, mg/dL & $1 \pm 0.2$ \\
\hline
\end{tabular}

${ }^{\mathrm{a}}$ Data are presented as Mean \pm SD. 
Khodabandehloo N et al.

Table 2. Characteristics of the Study Population by Age and Gender

\begin{tabular}{|c|c|c|c|c|c|c|}
\hline \multirow[t]{2}{*}{ Variable } & \multicolumn{2}{|c|}{$\operatorname{Male}(n=102)$} & \multicolumn{2}{|c|}{ Female $(n=130)$} & \multicolumn{2}{|c|}{ PValue } \\
\hline & $<75$ & $\geq 75$ & $<75$ & $\geq 75$ & Age & Gender \\
\hline Age, $y$ & $69 \pm 3$ & $79 \pm 3$ & $71 \pm 2$ & $79 \pm 2$ & & \\
\hline B12, pmol/L & $320 \pm 157$ & $2480 \pm 150$ & $328 \pm 140$ & $242 \pm 145$ & 0.001 & 0.46 \\
\hline Homocysteine, micmol/L & $20.6 \pm 7$ & $20 \pm 7$ & $17 \pm 7$ & $19.5 \pm 6$ & 0.89 & 0.002 \\
\hline Hemoglobin, g/dL & $15 \pm 1$ & $14 \pm 1$ & $13 \pm 1$ & $13 \pm 1$ & 0.001 & 0.002 \\
\hline MCV, FL & $91 \pm 7$ & $91.1 \pm 7$ & $92 \pm 6$ & $93 \pm 6$ & 0.23 & 0.94 \\
\hline Creatinine, mg/dL & $1.7 \pm 0.3$ & $1.7 \pm 0.3$ & $1.4 \pm 0.4$ & $1.5 \pm 0.5$ & 0.32 & 0.19 \\
\hline \multicolumn{2}{|l|}{ Variable } & \multicolumn{3}{|c|}{ Correlation Coefficienta } & \multicolumn{2}{|c|}{ P-Value $^{\mathrm{b}}$} \\
\hline \multicolumn{7}{|l|}{ Age } \\
\hline Hemoglobin & & \multicolumn{2}{|c|}{-0.339} & & \multicolumn{2}{|c|}{0.001} \\
\hline MCV & & \multicolumn{2}{|c|}{+0.161} & & \multicolumn{2}{|c|}{0.001} \\
\hline B12 & & \multicolumn{2}{|c|}{-0.337} & & \multicolumn{2}{|c|}{0.001} \\
\hline \multicolumn{7}{|l|}{ Creatinine } \\
\hline Homocysteine & & \multicolumn{2}{|c|}{+0.285} & & \multicolumn{2}{|c|}{0.001} \\
\hline \multicolumn{7}{|l|}{ B12 } \\
\hline Folate level & & \multicolumn{2}{|c|}{+0.269} & & \multicolumn{2}{|c|}{0.001} \\
\hline Homocysteine & & \multicolumn{2}{|c|}{-0.396} & & \multicolumn{2}{|c|}{0.001} \\
\hline \multicolumn{7}{|l|}{ Folate Level } \\
\hline Homocysteine & & \multicolumn{2}{|c|}{-0.24} & & \multicolumn{2}{|c|}{0.001} \\
\hline
\end{tabular}

a Spearman correlation.

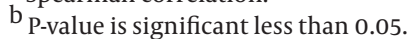

Table 4. Total Prevalence of B12 Deficiency and Its Prevalence by Age and Gender

\begin{tabular}{|c|c|c|c|c|c|}
\hline \multirow[t]{2}{*}{ Cutoff Variable } & \multicolumn{2}{|c|}{ Age } & \multicolumn{2}{|c|}{ Gender } & \multirow[t]{2}{*}{ All Patients } \\
\hline & $<75$ & $\geq 75$ & Male & Female & \\
\hline \multicolumn{6}{|l|}{ B12, pmol/L } \\
\hline$<150$ & $23(15.8)$ & $27(31.4)$ & $21(20.6)$ & $29(22.3)$ & $50(21.6)$ \\
\hline$<220$ & $46(31.5)$ & $47(54.7)$ & $39(38.2)$ & $54(41.5)$ & $93(40.1)$ \\
\hline $220-258$ & $12(8.2)$ & $13(15.1)$ & $13(12.7)$ & $12(9.2)$ & $25(10.8)$ \\
\hline$\geq 258$ & $88(60.3)$ & $26(30.2)$ & $50(49)$ & $64(49.2)$ & $114(49)$ \\
\hline \multicolumn{3}{|c|}{ Homocysteine, micmol/L } & \multicolumn{2}{|c|}{ B12 Level, pmol/L } & \\
\hline & \multicolumn{2}{|c|}{$<150$} & $<220$ & $220-258$ & $\geq 258$ \\
\hline$<15$ & \multicolumn{2}{|c|}{$5(2.2)$} & $16(6.9)$ & $7(3)$ & $50(21.6)$ \\
\hline$\geq 15$ & \multicolumn{2}{|c|}{$45(19.5)$} & $77(33.2)$ & $18(7.8)$ & $64(27.6)$ \\
\hline
\end{tabular}

\section{Discussion}

Vitamin B-12 deficiency is common in the elderly population. Typical causes of cobalamin deficiency in the elderly include pernicious anemia and food-bound malabsorption, but these causes explain less than a half of low vitamin B-12 concentrations. As shown in this study, there was a negative correlation between B12 concentration and patients' age. The results of the present study showed that the preva- lence of vitamin B-12 deficiency was similar in both genders, which is in contrast with previous reports $(12,13)$. Concentrations of homocysteine were elevated among those who had the lowest vitamin B-12 concentrations. Therefore, use of homocysteine in individuals with borderline vitamin concentrations may identify those with functional deficiency and those for whom treatment is indicated. 
Table 6. Prevalence of B12 Deficiency Regarding Homocysteine Level

\begin{tabular}{lc}
\hline Homocysteine & B12 Level \\
\hline$<15$ & 220 \\
\hline & $220-258$ \\
\hline 15 & $>258$ \\
& 220 \\
\hline & $220-258$ \\
& $>258$ \\
\hline
\end{tabular}

Measurement of serum or plasma cobalamin concentration is more specific, but varies depending on the method and particular laboratory. In adults, a concentration of $150 \mathrm{pmol} / \mathrm{L}(200 \mathrm{pg} / \mathrm{mL})$ is considered the lowest level for an adequate supply. In a developing deficiency, serum concentrations are maintained by depleting the stores of vitamin. Therefore, concentrations above the cut-off value of $150 \mathrm{pmol} / \mathrm{L}$ do not inevitably reflect a sufficient vitamin B12 status as shown in some studies, indicating that concentration is not a significant variable (14). On the other hand, if the cobalamin concentration is below this cut-off value, depleted stores can be assumed but not necessarily present (15). Based on studies, a serum cobalamin cutoff value of $<220 \mathrm{pmol} / \mathrm{L}(<300 \mathrm{pg} / \mathrm{mL})$ has been suggested, with more sensitive indicators of cobalamin status such as methylmalonic acid (MMA) and homocysteine (see below). Lindenbaum et al.(16) suggested a cut-off value of $220-258 \mathrm{pmol} / \mathrm{L}(300-350 \mathrm{pg} / \mathrm{mL}$ ) in the elderly population $(16,17)$. Individuals with low vitamin B12 concentrations exhibited significant elevations of MMA and homocysteine concentrations. However, some authors believe that the cut-off value of $150 \mathrm{pmol} / \mathrm{L}$ is too low. For example, in a sample of elderly patients with cobalamin concentrations below this value, $40 \%$ of subjects had increased serum MMA levels. In another study, as many as $80 \%$ of subjects aged 65 years with cobalamin concentrations $>148 \mathrm{pmol} / \mathrm{L}$ had increased MMA and homocysteine values $(15,16)$. Vazquez-Pedrazuela et al. observed vitamin B12 deficiency in 16.5\% of the study participants (a population of 65 years and over). A strong association was found between vitamin B12 deficiency and cardiac and cerebrovascular diseases, vascular risk factors and drugs administered in prevention of cardiac events and ischemic stroke. This study showed a higher prevalence of vitamin B12 deficiency in the elderly population compared to the literature (18). In our study, a threshold of $220 \mathrm{pmol} / \mathrm{L}$ (300 pg/mL) was recognized as a desirable status indicator in the elderly $(15,18,19)$. In case of concentrations below 220 pmol/L, further diagnostic measures are necessary. These early indicators of cobalamin deficiency could be elevated plasma homocysteine, elevated serum MMA and decreased serum holotrans- cobalamin (holoTC) $(15,20,21)$. Elevated homocysteine is an important indicator of vitamin B12 deficiency and may indicate a low vitamin B6 status. In elderly with normal folate and vitamin B6 levels, elevated homocysteine is generally a consequence of cobalamin deficiency (15, 22). Our study showed an inverse association that was approximately linear and graded in the proportions with elevated homocysteine with decreasing concentrations of vitamin B-12. However, the cuto-ff point of $>15 \mathrm{micmol} / \mathrm{L}$ for homocysteine can be used to distinguish individuals with elevated concentrations from those with normal concentrations. Different levels of total homocysteine in plasma were suggested as normal: $<14 \mathrm{micmol} / \mathrm{L}(23$, 24) 5-13.6 micmol/L $(25,26)$ and 4.9-11.7 micmol/ L $(27,28)$. Since many studies showed that the prevalence and mortality of cardiovascular disease (CVD) increased if a concentration of $10 \mathrm{micmol} / \mathrm{L}$ was exceeded (28-31), this limit has been suggested as desirable $(32,33)$. Values of $>12$ - $30 \mathrm{micmol} / \mathrm{L}$ are classified as moderate hyperhomocysteinemia $(22,34)$. Although MMA is a more specific and sensitive indicator of cobalamin status, we did not have the required kits for measuring its level in our patients. Elevated MMA is a direct metabolic consequence of vitamin B12 deficiency $(35,36)$. Therefore, MMA is an important biochemical marker of cobalamin status $(16,19,25$, $26,37,38)$. The reference range of serum MMA concentrations in healthy adults is $73-271 \mathrm{nmol} / \mathrm{L}(39,40)$. In elderly individuals, the prevalence of subnormal cobalamin concentration varies between $10 \%$ and $43 \%$ depending on the diagnostic criteria $(31,39,41,42)$. If the previously considered threshold of $150 \mathrm{pmol} / \mathrm{L}(200 \mathrm{pg} / \mathrm{mL})$ for a normal vitamin B12 status is used, only 10-15\% of the elderly population is classified as cobalamin deficient, which is about $21.6 \%$ of the cobalamin deficient patients in this study. This shows significant difference of B12 deficiency with other countries, even with this cut-off point $(<150$ pmol/L). A study showed that the prevalence of combined B12 insufficiency and supraphysiological concentrations of serum folate may have increased with folic acid food fortification in Canadian women aged 65 years and older who underwent concomitant clinical testing of serum folate and B12 (43). The threshold of $<220 \mathrm{pmol} / \mathrm{L}(<300$ $\mathrm{pg} / \mathrm{mL}$ ) is considered as a desirable status indicator in the elderly $(15,16,32,34,35)$ and otherwise more sensitive markers such as blood concentration of homocysteine or methylmalonic acid are used. Then, the prevalence of cobalamin deficiency rises to up to $43 \%(4,44-46)$. According to our study, a possible approach to screen vitamin B-12 deficiency starts with measurement of vitamin B-12. If individuals have vitamin B-12 concentrations below $220 \mathrm{pmol} / \mathrm{L}$, more detailed investigations should be undertaken to discover the underlying cause and the best treatment. If patients have vitamin B-12 concentrations between 220 and $258 \mathrm{pmol} / \mathrm{L}$, homocysteine may assist in identifying those who require more detailed examination and treatment. Therefore, in this case, the frequency (\%) of patients with cobalamin deficiency would be about 
$47.9 \%$, which is higher than other studies (43\%) $(14,15,19$, 32). According to the findings of previous studies, use of supplements or enriched foods reduces the prevalence of cobalamin deficiency in the elderly $(15,41,42,47)$. In Rajan et al. study on elderly aged $65-100$ years, $46 \%$ of screened patients reported regularly taking a source of synthetic cobalamin. Nevertheless, $13 \%$ were classified as vitamin B12 deficient because of serum cobalamin concentrations $<220 \mathrm{pmol} / \mathrm{L}$ and MMA concentrations $>271$ $\mathrm{nmol} / \mathrm{L}$. In the elderly, supplementation with less than $50 \mathrm{micg} /$ day vitamin B12 does not seem to prevent a poor cobalamin status (19). Because of the high prevalence of vitamin B12 deficiency and its association with neurocognitive diseases, daily use of cobalamin supplements of $>50 \mathrm{micg} /$ day is recommended for elderly people aged 60 years and older. This preventive measure has no side effects and would be useful with respect to a risk-benefit analysis. Due to insecure cobalamin supply, it is necessary to monitor the status of vitamin B12 regularly in elderly people ( $>60$ years). Since serum vitamin B12 is not a reliable indicator of subclinical cobalamin deficiency, measurement of more sensitive indicators like MMA and homocysteine should be considered. In patients with diagnosed cobalamin deficiency, the above mentioned preventive doses of cobalamin are insufficient (15). Shobha et al. in their study highlighted the association of dietary habits of urban south Indian elderly and plasma vitamin B12, folate and homocysteine levels with cognitive status and impact of vitamin supplementation on normalization of the same. They found that daily vitamin B12 intake was 3.5 times higher than the FDA recommendation contrary to the belief that dietary intake would be low in Indian population as many are vegetarian (57\%). However, no correlation was detected between plasma vitamin B12 and cognitive status in elderly population (48). Conclusions: The prevalence of vitamin B12 deficiency was higher in this study compared to other studies. Considering the consequences of vitamin B12 deficiency, more attention should be paid to this vitamin and preventive measures should be devised to reduce its deficiency.

\section{Acknowledgements}

The authors would like to thank the elderly research center, University of Social Welfare and Rehabilitation Sciences, for their support.

\section{Authors' Contributions}

Nilufar Khodabandehloo: performed the experimental work; Masoud Vakili and Zahra Hashemian: planning of the project and analysis of data; Hadi Zare Zardini: writing the paper.

\section{Funding/Support}

This work was supported by Tehran University of Medical Sciences, Tehran, Iran.

\section{References}

1. Bjorkegren K, Svardsudd K. Reported symptoms and clinical findings in relation to serum cobalamin, folate, methylmalonic acid and total homocysteine among elderly Swedes: a population-based study. J Intern Med. 2003;254(4):343-52.

2. Carmel R, Gott PS, Waters CH, Cairo K, Green R, Bondareff W, et al. The frequently low cobalamin levels in dementia usually signify treatable metabolic, neurologic and electrophysiologic abnormalities. Eur J Haematol. 1995;54(4):245-53.

3. Allen RH, Stabler SP, Lindenbaum J. Relevance of vitamins, homocysteine and other metabolites in neuropsychiatric disorders. Eur J Pediatr. 1998;157 Suppl 2:S122-6.

4. Nilsson-Ehle H. Age-related changes in cobalamin (vitamin B12) handling. Implications for therapy. Drugs Aging. 1998;12(4):277-92.

5. Haller J. The vitamin status and its adequacy in the elderly: an international overview. Int J Vitam Nutr Res. 1999;69(3):160-8.

6. Agarwal R. Vitamin B(1)(2) deficiency \& cognitive impairment in elderly population. Indian J Med Res. 2011;134:410-2.

7. Almeida OP, McCaul K, Hankey GJ, Norman P, Jamrozik K, Flicker L. Homocysteine and depression in later life. Arch Gen Psychiatry. 2008;65(11):1286-94.

8. Quadri P, Fragiacomo C, Pezzati R, Zanda E, Tettamanti M, Lucca U. Homocysteine and B vitamins in mild cognitive impairment and dementia. Clin Chem Lab Med. 2005;43(10):1096-100.

9. Shea TB, Lyons-Weiler J, Rogers E. Homocysteine, folate deprivation and Alzheimer neuropathology. J Alzheimers Dis. 2002;4(4):261-7.

10. Quadri P, Fragiacomo C, Pezzati R, Zanda E, Forloni G, Tettamanti $\mathrm{M}$, et al. Homocysteine, folate, and vitamin B-12 in mild cognitive impairment, Alzheimer disease, and vascular dementia.Am JClin Nutr. 2004;80(1):114-22.

11. Kasper DL, Braunwald E, Fauci AS, Hauser SL, Longo DL, Jameson JL. Harrison's principles of internal medicine. 17th ed. New York: McGraw-Hill; 2008.

12. Vogiatzoglou A, Smith AD, Nurk E, Berstad P, Drevon CA, Ueland PM, et al. Dietary sources of vitamin B-12 and their association with plasma vitamin B-12 concentrations in the general population: the Hordaland Homocysteine Study. Am J Clin Nutr. 2009;89(4):1078-87.

13. Carmel R, Green R, Jacobsen DW, Rasmussen K, Florea M, Azen C. Serum cobalamin, homocysteine, and methylmalonic acid concentrations in a multiethnic elderly population: ethnic and sex differences in cobalamin and metabolite abnormalities. Am J Clin Nutr. 1999;70(5):904-10.

14. Carmel R. Current concepts in cobalamin deficiency. Annu Rev Med. 2000;51:357-75.

15. Wolters M, Strohle A, Hahn A. Cobalamin: a critical vitamin in the elderly. Prev Med. 2004;39(6):1256-66.

16. Lindenbaum J, Rosenberg IH, Wilson PW, Stabler SP, Allen RH Prevalence of cobalamin deficiency in the Framingham elderly population. Am J Clin Nutr. 1994;60(1):2-11.

17. Yao Y, Yao SL, Yao SS, Yao G, Lou W. Prevalence of vitamin B12 deficiency among geriatric outpatients. J Fam Pract. 1992;35(5):524-8.

18. Vazquez-Pedrazuela Mdel C, Canton-Alvarez MB, de la FuenteHontanon Mdel C, Soloaga-Morales A, Collazos-del Castillo JM, Sertal-Parcero R. [Vitamin B12 and folic acid deficiency in the population over 65 years: a descriptive study]. Rev Esp Geriatr Gerontol. 2012;47(6):259-61.

19. Rajan S, Wallace JI, Beresford SA, Brodkin KI, Allen RA, Stabler SP. Screening for cobalamin deficiency in geriatric outpatients: prevalence and influence of synthetic cobalamin intake. J Am Geriatr Soc. 2002;50(4):624-30.

20. Herrmann W, Obeid R, Schorr H, Geisel J. Functional vitamin B12 deficiency and determination of holotranscobalamin in populations at risk. Clin Chem Lab Med. 2003;41(11):1478-88.

21. Stabler SP, Lindenbaum J, Allen RH. The use of homocysteine and other metabolites in the specific diagnosis of vitamin B-12 deficiency. J Nutr. 1996;126(4 Suppl):1266S-72S.

22. Selhub J, Jacques PF, Wilson PW, Rush D, Rosenberg IH. Vitamin status and intake as primary determinants of homocysteinemia in an elderly population. JAMA. 1993;270(22):2693-8. 
23. Joosten E, Lesaffre E, Riezler R. Are different reference intervals for methylmalonic acid and total homocysteine necessary in elderly people? Eur J Haematol. 1996;57(3):222-6.

24. Herrmann W. The importance of hyperhomocysteinemia as a risk factor for diseases: an overview. Clin Chem Lab Med. 2001;39(8):666-74.

25. Ubbink JB, Becker PJ, Vermaak WJ, Delport R. Results of B-vitamin supplementation study used in a prediction model to define a reference range for plasma homocysteine. Clin Chem. 1995;41(7):1033-7.

26. Green R, Kinsella LJ. Current concepts in the diagnosis of cobalamin deficiency. Neurology. 1995;45(8):1435-40.

27. Gerhard GT, Duell PB. Homocysteine and atherosclerosis. Curr Opin Lipidol. 1999;10(5):417-28.

28. Naurath HJ, Joosten E, Riezler R, Stabler SP, Allen RH, Lindenbaum $\mathrm{J}$. Effects of vitamin B12, folate, and vitamin B6 supplements in elderly people with normal serum vitamin concentrations. Lancet 1995;346(8967):85-9.

29. Wolters M, Hermann S, Hahn A. B vitamin status and concentrations of homocysteine and methylmalonic acid in elderly German women. Am JClin Nutr. 2003;78(4):765-72.

30. Bjorkegren K, Svardsudd K. Elevated serum levels of methylmalonic acid and homocysteine in elderly people. A population-based intervention study. J Intern Med.1999;246(3):317-24.

31. Pennypacker LC, Allen RH, Kelly JP, Matthews LM, Grigsby J, Kaye $\mathrm{K}$, et al. High prevalence of cobalamin deficiency in elderly outpatients. JAm Geriatr Soc. 1992;40(12):1197-204

32. Wolters M, Strohle A, Hahn A. [Age-associated changes in the metabolism of vitamin $\mathrm{B}(12)$ and folic acid: prevalence, aetiopathogenesis and pathophysiological consequences]. Z Gerontol Geriatr. 2004;37(2):109-35.

33. Bjorkegren K, Svardsudd K. Serum cobalamin, folate, methylmalonic acid and total homocysteine as vitamin B12 and folate tissue deficiency markers amongst elderly Swedes--a populationbased study. JIntern Med. 2001;249(5):423-32.

34. Herrmann W, Schorr H, Bodis M, Knapp JP, Muller A, Stein G, et al. Role of homocysteine, cystathionine and methylmalonic acid measurement for diagnosis of vitamin deficiency in high-aged subjects. Eur J Clin Invest. 2000;30(12):1083-9.

35. Klee GG. Cobalamin and folate evaluation: measurement of methylmalonic acid and homocysteine vs vitamin $\mathrm{B}(12)$ and folate. Clin Chem. 2000;46(8 Pt 2):1277-83.
36. Baik HW, Russell RM. Vitamin B12 deficiency in the elderly. Annu Rev Nutr. 1999;19:357-77.

37. Stabler SP, Lindenbaum J, Allen RH. Vitamin B-12 deficiency in the elderly: current dilemmas. Am J Clin Nutr. 1997;66(4):741-9.

38. Omenn GS, Beresford SA, Motulsky AG. Preventing coronary heart disease: B vitamins and homocysteine. Circulation. 1998;97(5):421-4

39. Stanger O, Herrmann W, Pietrzik K, Fowler B, Geisel J, Dierkes J, et al. DACH-LIGA homocystein (german, austrian and swiss homocysteine society): consensus paper on the rational clinica use of homocysteine, folic acid and B-vitamins in cardiovascular and thrombotic diseases: guidelines and recommendations. Clin Chem Lab Med. 2003;41(11):1392-403.

40. Quinn K, Basu TK. Folate and vitamin B12 status of the elderly. Eur JClin Nutr. 1996;50(6):340-2.

41. Koehler KM, Romero LJ, Stauber PM, Pareo-Tubbeh SL, Liang HC, Baumgartner RN, et al. Vitamin supplementation and other variables affecting serum homocysteine and methylmalonic acid concentrations in elderly men and women. J Am Coll Nutr 1996;15(4):364-76.

42. Garcia AA, Haron Y, Evans LR, Smith MG, Freedman M, Roman GC Metabolic markers of cobalamin deficiency and cognitive func tion in normal older adults. J Am Geriatr Soc. 2004;52(1):66-71.

43. Ray JG, Vermeulen MJ, Langman LJ, Boss SC, Cole DE. Persistence of vitamin B12 insufficiency among elderly women after folic acid food fortification. Clin Biochem. 2003;36(5):387-91.

44. Grasbeck R. Biochemistry and clinical chemistry of vitamin B12 transport and the related diseases. Clin Biochem. 1984;17(2):99-107.

45. Nygard O, Refsum H, Ueland PM, Vollset SE. Major lifestyle determinants of plasma total homocysteine distribution: the Hordaland Homocysteine Study. Am J Clin Nutr. 1998;67(2):263-70.

46. Hurwitz A, Brady DA, Schaal SE, Samloff IM, Dedon J, Ruhl CE. Gastric acidity in older adults. JAMA. 1997;278(8):659-62.

47. Seal EC, Metz J, Flicker L, Melny J. A randomized, double-blind, placebo-controlled study of oral vitamin B12 supplementation in older patients with subnormal or borderline serum vitamin B12 concentrations. J Am Geriatr Soc. 2002;50(1):146-51.

48. Shobha V, Tarey SD, Singh RG, Shetty P, Unni US, Srinivasan K, et al. Vitamin B(1)(2) deficiency \& levels of metabolites in an apparently normal urban south Indian elderly population. Indian J Med Res. 2011;134:432-9. 